\title{
THE ELECTROCARDIOGRAM IN FRIEDREICH DISEASE
}

\author{
BY \\ WILLIAM EVANS AND GORDON WRIGHT \\ From the Cardiac Department of the London Hospital \\ Received May 5, 1942
}

It has been the custom to regard Friedreich disease as affecting only the central nervous system, but an examination of 38 cases has convinced us that the heart also is often affected.

When recording the clinical and pathological findings in a patient with Friedreich's ataxia who had been treated for heart failure at Guy's Hospital and the London Hospital, Newton Pitt (1887) said that not enough attention had been paid to the circulatory system in this disease: in his patient, heart failure had been an outstanding feature of the last phase of the fatal illness and was the cause of death. The case records of Friedreich disease published since deal chiefly with changes in the nervous system, and reference to symptoms connected with the heart has generally been either casual or missing. Yet a few cases that showed some abnormality of the heart have been recorded. Histological changes in the myocardium were described by Lannois and Porot (1905) and by Guizzetti (1933). Heart failure was reported by Omerod (1885) and Pitt (1887). Electrocardiographic irregularities have been described occasionally during the past ten years. Guillain and Mollaret (1932) found inversion of the T wave in leads II and III in one case, and a prolonged P-R interval with right axis deviation in another; so impressed were they by these changes that they spoke of the " cardiobulbar syndrome." Nodal arrhythmia, right electrical axis deviation, and a diphasic or inverted $\mathrm{T}$ wave in lead I were shown in an electrocardiogram published by Rathery, Mollaret, and Sterne (1934). Progressive cardiographic changes were watched for two years in a patient by Guillain and Mollaret (1934), and the last tracing showed inversion of $T_{2}$ and $T_{3}$. A similar curve was found in a child by Debré, Marie, Soulié, and de Font-Réaulx (1936). In eight patients examined by van Bogaert (1936) the cardiogram showed inversion of $T_{1}$ and $T_{2}$ in two cases and of $\mathrm{T}_{2}$ and $\mathrm{T}_{3}$ in another two; there were minor changes in two of the remaining four.

We became interested in the subject when a young woman (Case 1) suffering from this condition was found with Stokes-Adams attacks, and when we were told that her brother, similarly affected, had died at the age of 18 during an attack. We arranged to examine the heart specially in other cases of Friedreich disease, and in this paper we give the findings in 38 patients assembled for the 


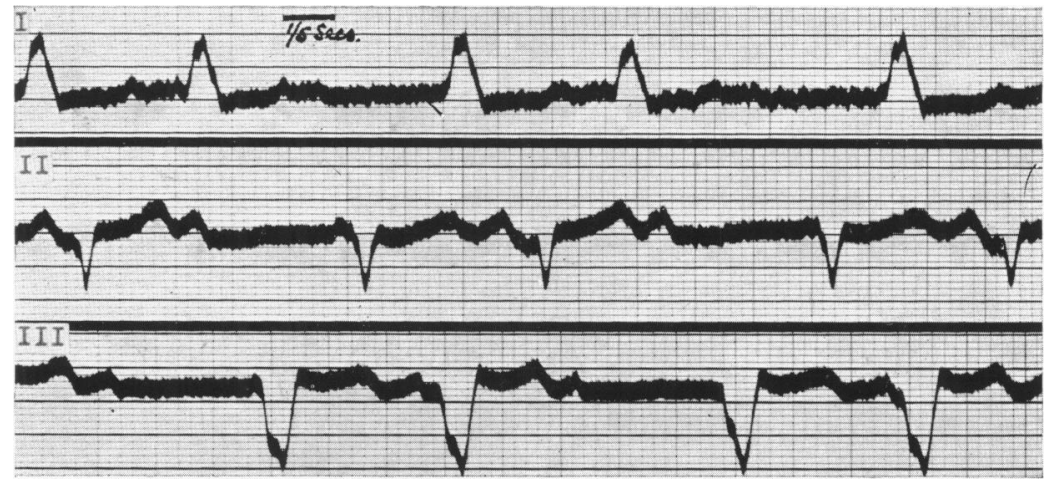

Fig. 1.-Female, aged 22 (Case 1). Complete and left bundle branch block with extrasystoles. Fig. 1, 2, and 3 have been reduced to $2 / 3$.

investigation. In every case the diagnosis of the condition had been made by a neurologist, and a further routine examination was carried out before admitting the patient into the series. A limb lead electrocardiogram was recorded, and whenever an abnormality of the $\mathrm{T}$ wave showed in lead $\mathrm{I}$, lead IVR was taken as well. Other chest leads were sometimes recorded. Cardioscopy was carried out in 34 patients, but not in 4 who were bedridden.

\section{RESULTS}

Clinical Examination of the Heart.-In only one patient (Case 1) was the pulse abnormal, and then it was slow from heart block and irregular from

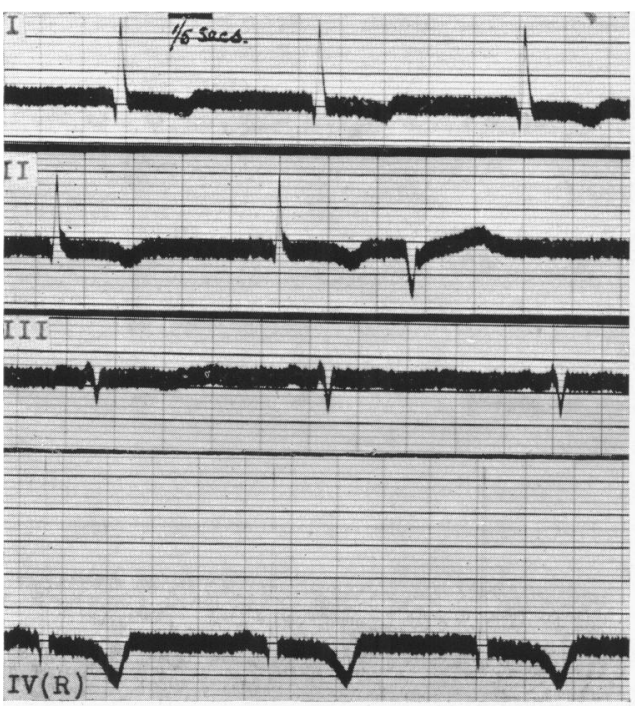

FIG. 2. - Male aged 50 (Case 2). T inverted in leads I, II, and IVR.

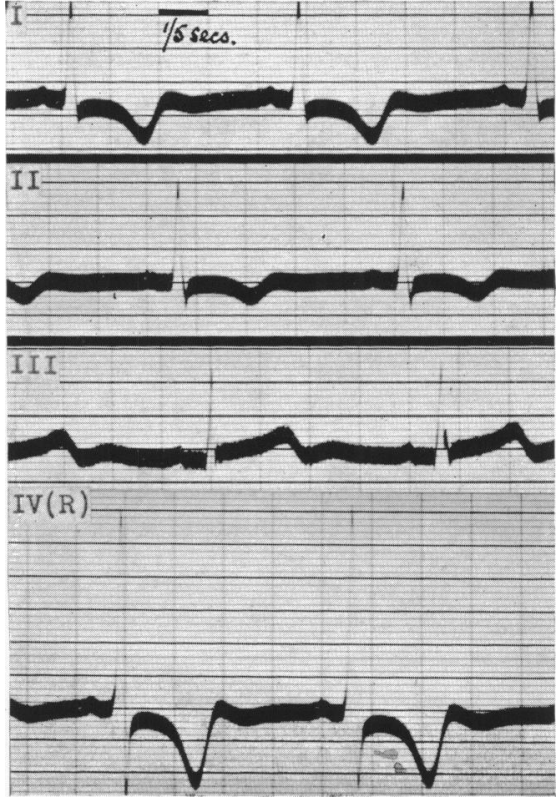

FIG. 3.-Male aged 22 (Case 3). T inverted in leads I, II, and IVR. 
extrasystoles; the brother of this patient, who died in a Stokes-Adams attack at another hospital, is not included in this series because a cardiogram was not taken. None showed significant changes in blood pressure. The apex beat was often displaced outwards on account of scoliosis but not once from cardiac

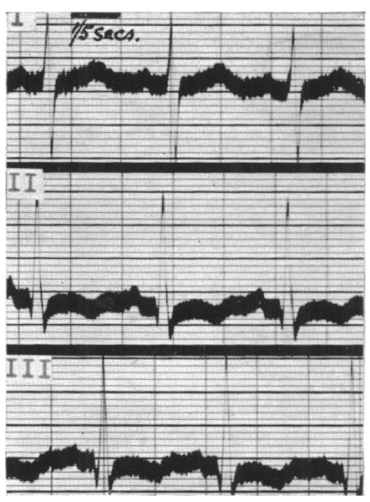

Fig. 4.-Female, aged 20 (Case 4). $T$ inverted in leads II and III.

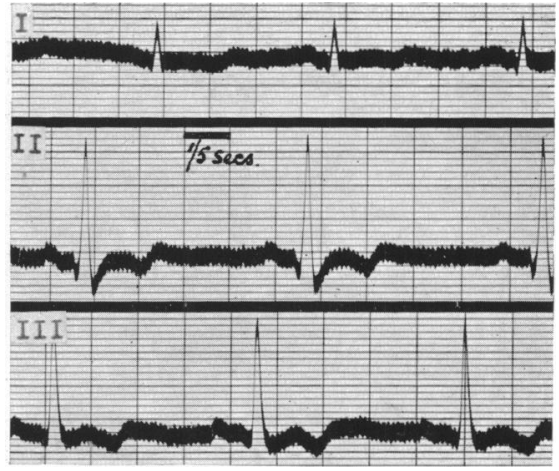

Fig. 5.-Male, aged 26 (Case 5). T low in lead $\mathrm{I}$, and inverted in leads II and III.

hypertrophy. Noticeable murmurs were never found, and no valvular disease, either congenital or acquired. Except in four bedridden patients cardioscopy (i.e. radioscopy of the heart) was a routine method of examination, but it failed to demonstrate any gross changes; slight enlargement of the heart to the left,

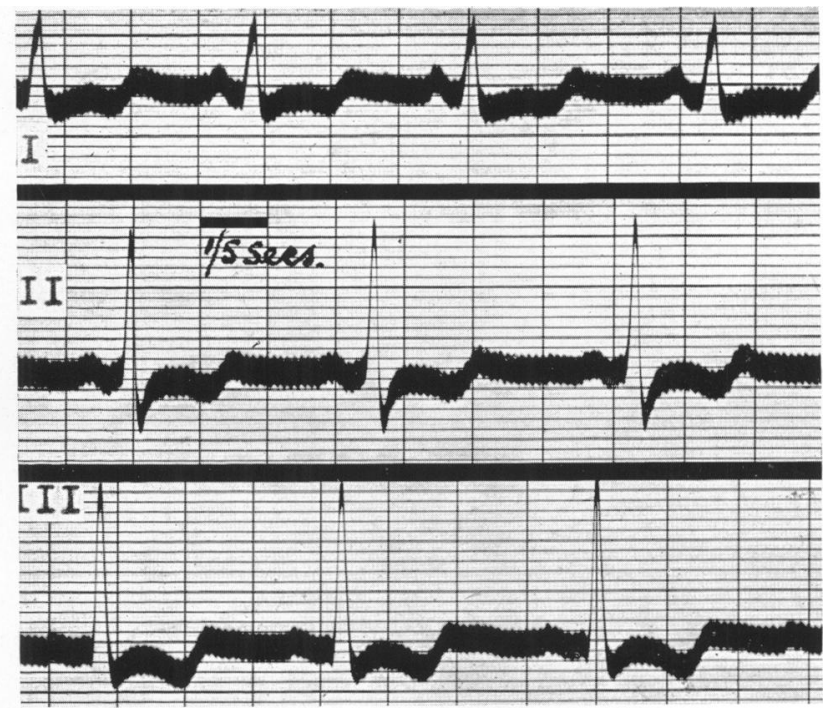

Fig. 6.-Female, aged 32 (Case 6). T wave inverted in leads I, II, and III.

sometimes confined to the toe of the left ventricle, was found in 8 patients, and 5 of these had prominent cardiographic changes.

Cardiographic Changes.-The electrocardiogram was abnormal in 12 of the 38 patients. In 10 others it was not strictly physiological, but these lesser 
changes might have resulted from the deformity of the chest, which was a prominent feature of some of the cases.
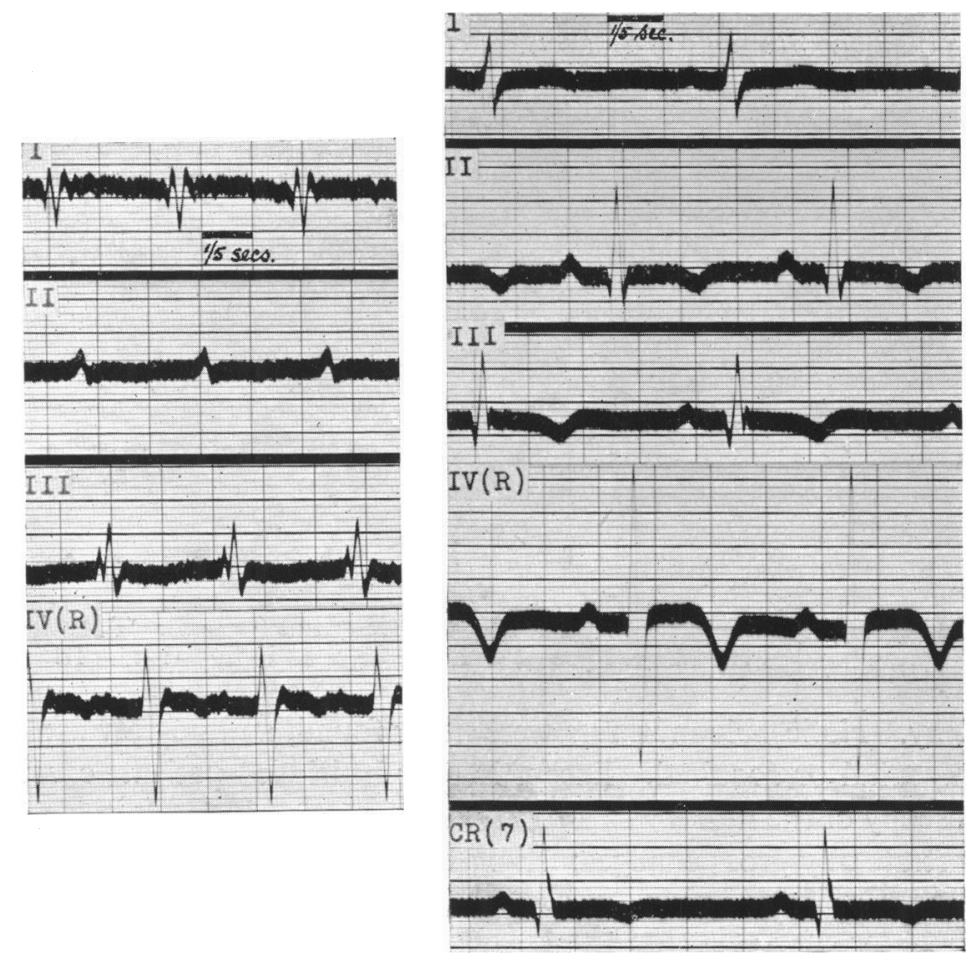

Fig. 7.- Male, aged 52 (Case 7). T flat in lead I, slightly inverted in leads II and III, and inverted in IVR.

Fig. 8.-Male, aged 20 (Case 9). T just upright in lead I, inverted in leads II, III, IVR and $\mathrm{CR}_{\mathbf{7}}$.

Fig. $7-14$ have been reduced to $7 / 8$.
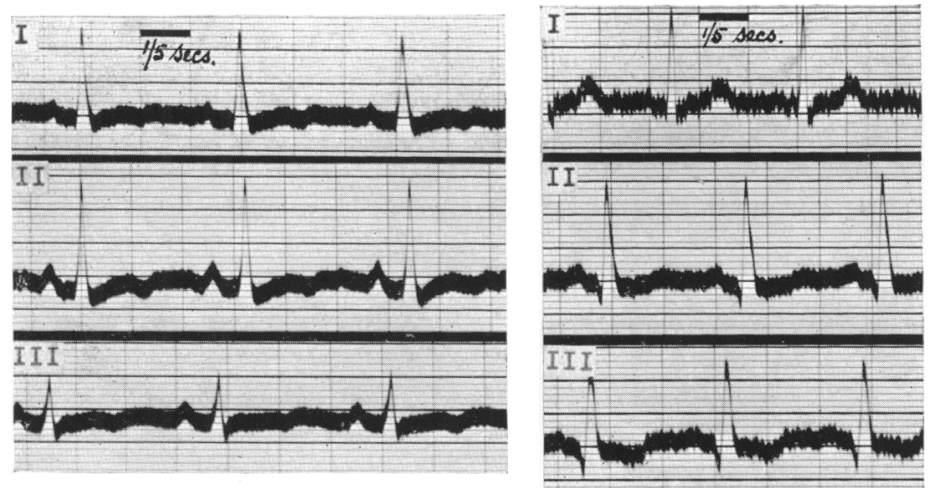

FIG. 9.-Female, aged 33 (Case 8). T inverted FIG. 10.-Female, aged 15 (Case 11). T just in leads I, II, and III. upright in lead II and diphasic in lead III.

Among the 12 abnormal cardiograms there was complete heart block and left bundle branch block in one (Fig. '1), inversion of the $T$ wave conforming 
to the $\mathrm{T}_{1}$ type of cardiac infarction of Parkinson and Bedford (1927) in three (Fig. 2, 3, and 12), and to the $T_{3}$ type in three patients (Fig. 4, 10, and 11): In 5 cases (Fig. 5, 6, 7, 8, and 9) the $\mathrm{T}$ wave was low and usually inverted in all three limb leads.

In 5 of the 10 cases showing minor changes in the cardiogram the $S$ wave

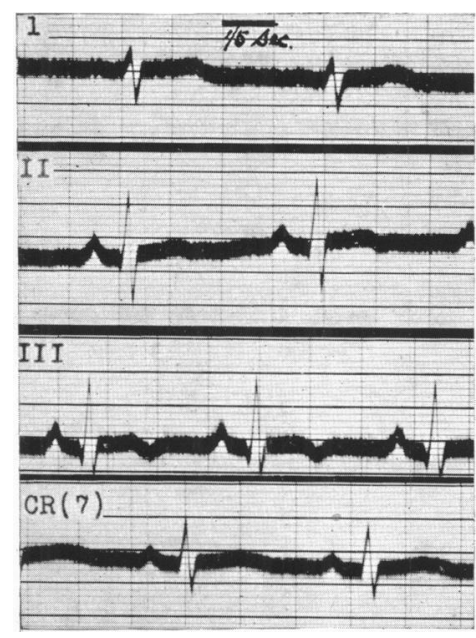

FIG. 11.-Male, aged 20 (Case 10). T inverted in lead III and just upright in leads I, II, and $\mathrm{CR}_{7}$.

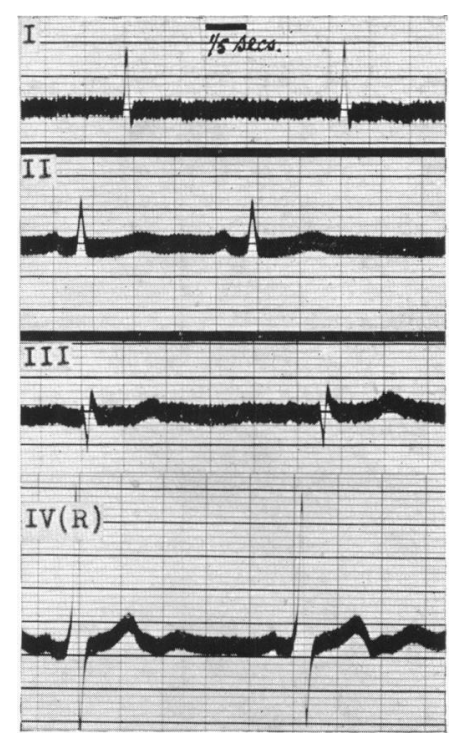

FIG. 12.-Male, aged 52 (Case 12). $\quad \mathrm{T}$ inverted in lead I.

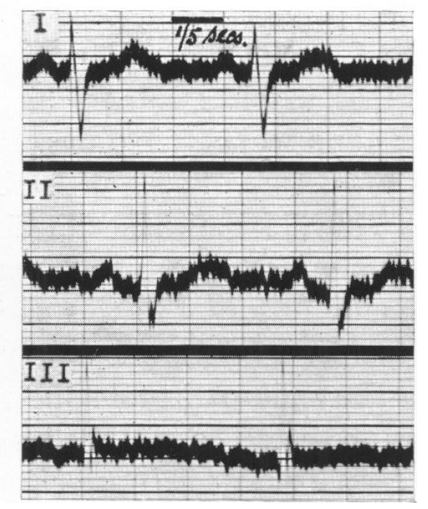

FIG. 13.-Female, aged 26 (Case 13): Deep and slurred $S$ in leads I and II.

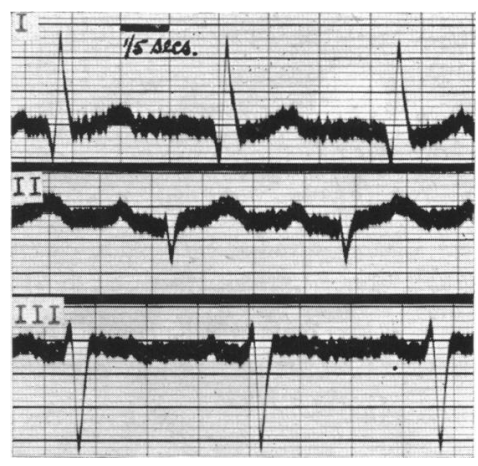

Fig. 14.-Male, aged 19 (Case 18). Deep S in leads II and III; deep Q in lead I.

was deep and often slurred in lead I and usually in lead II (Fig. 13), and in the remaining 5 there were corresponding changes in leads II and III (Fig. 14).

We did not expect to find any correlation between the incidence of cardiographic abnormalities and the distribution of lesions in the nervous system, 
but it seemed worth while to inquire. The neurological findings were therefore tabulated in relation to the cardiographic changes in Table I, and more fully in Tables II, III, and IV at the end of the paper.

TABLE I

Abnormal Signs in the Central Nervous System and Heart in 38 Patients with FriedReICH DISEASE

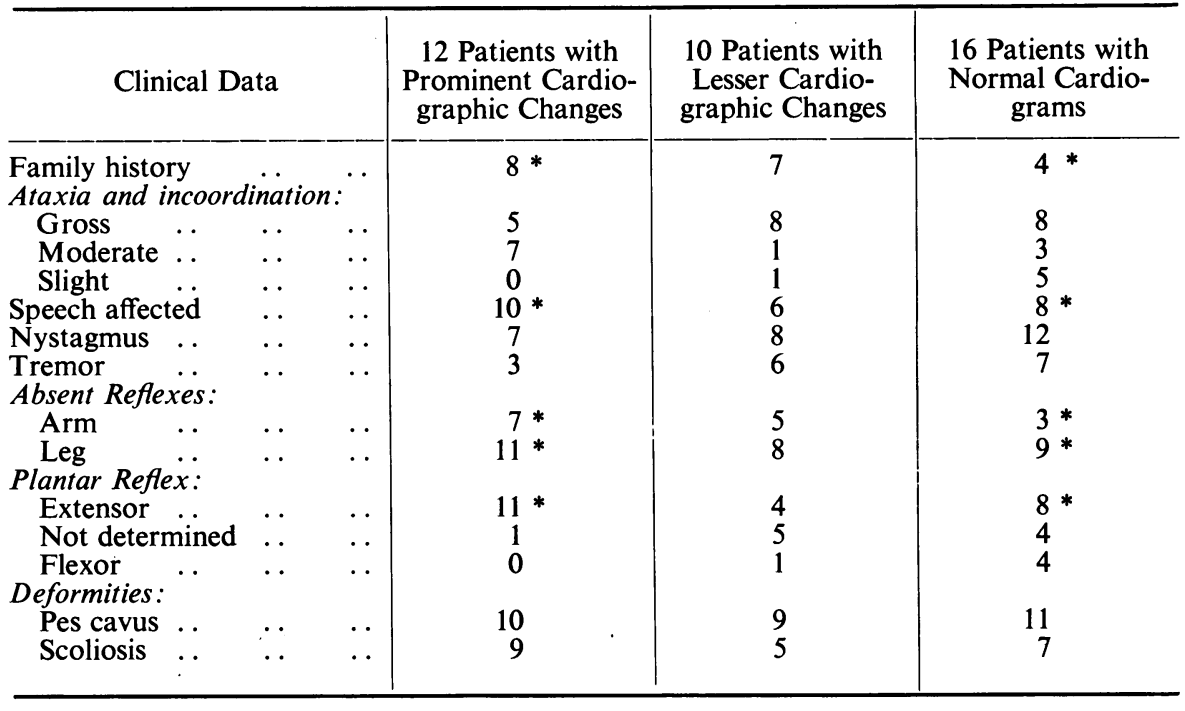

* Denotes a significant difference.

The incidence of cardiographic changes was in no way related to age or sex, or to the time of onset of the disease. Two neurological signs, absence of tendon reflexes, and extensor response of the plantar reflex, occurred in the patients with cardiographic irregularities so frequently as to be significant. Furthermore, reference to Table I shows that involvement of the nervous system as a whole was greatest in those with abnormal cardiograms.

The association of a family history of Friedreich disease with abnormal cardiographic changes was most striking. Thus 15 patients with abnormal cardiograms (gross changes in 8) had one or more relatives similarly affected, while only 4 with normal tracings had a family history. In this connection another feature came to light; that affected members of the one family tended to show the same cardiographic changes. The only patient in the series to show complete heart block and Stokes-Adams disease (Case 1), had a brother similarly affected. A sister and younger brother of Case 1 (Cases 17 and 18) showed comparable but lesser cardiographic changes. Another (Case 3), with inversion of $T_{1}$ and $T_{2}$, had a sister (Case 4) with inversion of $T_{2}$ and $T_{3}$. The cardiograms in a brother and sister (Cases 5 and 6) demonstrated inversion of $\mathrm{T}_{2}$ and $\mathrm{T}_{3}$. Twin brothers showed the same type of cardiographic changes although these were more severe in one (Case 9) than the other (Case 10). Two brothers and a sister (Cases 14, 15, and 16) exhibited similar tracings, but in two brothers (Cases 19 and 35) the curves were dissimilar. That identical physical 
signs in relatives with Friedreich disease are not confined to the electrocardiogram was shown by two brothers (Cases 19 and 35) with primary optic atrophy, whose sister also was blind from birth and the subject of Friedreich disease.

\section{The Meaning of the Cardiographic Findings}

In the light of electrocardiographic changes in cardiac infarction it would be expected that the heart lesion in Friedreich disease usually lies in the muscle or in the conducting tissues. In those cases with a tracing similar to that found in cardiac infarction it is likely that the changes in the myocardium have a distribution in the anterior or posterior part of the heart, comparable with the areas involved when either the left or right coronary artery becomes occluded. In those patients with a "coronary type" of curve none so far have angina pectoris, and involvement of the coronary artery in Friedreich is unlikely. In a case with a cardiogram showing a Pardee type of curve, Laubry and de Balsac (1936) injected the coronary circulation with a mercurial preparation at necropsy, and in a subsequent radiogram they found no abnormality in the course of the coronary arteries. Our interpretation of the significance of the cardiographic changes also gains support from the histological findings in cases reported by Pitt (1887) and by Lannois and Porot (1905). Pitt described enlargement of the heart from hypertrophy of its walls and dilatation of its cavities. On microscopical examination he found that the muscle was healthy in many places; in some places it had undergone granular degeneration, and in others it had been replaced completely by loose and vascularized fibrous tissue, which in parts was crowded with small cells. D. S. Russell (1941) states that the heart in Friedreich disease may show a widespread change consisting of enlargement caused by thickening of the muscle and diffuse fibrosis; microscopical examination demonstrates fatty degeneration of the muscle fibres with slight chronic inflammatory infiltration and fibrosis.

It is not known yet whether the significant cardiographic changes predict the eventual onset of heart failure. Anyhow it is improbable that failure ever takes place in Friedreich disease when the electrocardiogram is normal, but the proximity of the event is likely to be judged best by the degree of cardiac enlargement determined by cardioscopy. The outlook is certainly ominous when the cardiogram signifies involvement of the bundle of His and especially when auriculo-ventricular dissociation has caused Stokes-Adams disease.

As a rule the diagnosis of Friedreich disease is straightforward after examination of the nervous system. When it is in doubt the electrocardiogram may help, for an abnormal tracing of the type described here supports the diagnosis although a normal curve does not exclude it.

\section{Summary AND CONCLUSIONS}

The electrocardiogram in 38 patients with Friedreich disease was specially studied. This investigation has convinced us that the condition may sometimes be as much an affection of the heart as of the nervous system. 
In only one patient, with Stokes-Adams disease, did clinical examination of the heart show any abnormality; in his case the pulse was slow from complete heart block and irregular from extrasystoles.

Cardiscopy, carried out in all except 4 bedridden patients, showed slight enlargement of the left ventricle in 8 , and 5 of these had prominent cardiographic changes.

The cardiogram showed conspicuous or significant changes in 12 of the 38 patients. There were slight changes in another 10 . In the remaining 16 the curve was physiological. In the first group 1 patient had complete heart block, 3 had a $T_{1}$ type of coronary curve, and 3 had a $T_{3}$ type of curve. In 5 the $\mathrm{T}$ wave was low and usually inverted in all three limb leads. In 5 of 10 patients showing lesser changes, the $\mathrm{S}$ wave was deep and slurred in lead I and usually in lead II, and similarly in leads II and III in the other 5 patients.

When the relation of abnormal signs in the nervous system to the cardiographic changes was examined, it was found that absence of tendon reflexes and extensor response of the plantar reflex were more common in patients with abnormal cardiograms. In respect of other nervous signs it may be said generally that they were more widespread in patients with the more conspicuous cardiographic changes. Of greater significance appeared to be the high incidence of a family history of Friedreich disease in those showing cardiographic changes. Thus 15 out of 22 patients with abnormal cardiograms ( 8 of them showing gross changes) had one or more relatives, usually a brother or sister, similarly affected, while only 4 out of 16 patients with normal curves provided this family history. The affected members of the same family tended to show identical cardiographic changes.

The electrocardiogram may help to establish the diagnosis of Friedreich disease when the neurological manifestations are not altogether typical of the condition; an abnormal tracing lends support to the diagnosis, but a normal curve does not exclude it. In prognosis too the cardiogram can be of assistance; when it proves involvement of the bundle of His it may foretell auriculoventricular dissociation and Stokes-Adams disease with its ominous outlook. The exact significance of a " coronary type" of curve is not known yet, but it is probable that only such cases are prone to develop heart failure, although the proximity of this event may be more closely related to the degree of cardiac enlargement, which is best determined by cardioscopy.

For these reasons we would say that the investigation of a patient with Friedreich disease is incomplete without electrocardiography and cardioscopy.

We are grateful to Dr. A. Hunter, First Assistant to the Department, who helped us in many ways, and to the following who assisted us in the collection of cases: Dr. W. R. Brain, Dr. A. E. Clark-Kennedy, Dr. C. Ellingworth, Dr. A. Feiling, Dr. A. R. Gilchrist, Dr. L. J. Grant, Dr. W. Harris, Dr. N. G. Hulbert, Dr. D. Hunter, Dr. R. Kempthorne, Mr. I. Lewis, Dr. R. Mackay, Dr. J. McM. Mennell, Mr. A. M. A. Moore, Dr. E. A. B. Pritchard, Dr. B. Russell, Dr. E. M. Sawdon, Dr. P. H. S. Shaw, Dr. B. Varling, and Dr. M. W. Warren.

We wish to thank Dr. John Parkinson, Physician to the Cardiac Department, for his helpful criticism of this paper. 


\section{REFERENCES}

van Bogaert, A. and L. (1936). Arch. Mal. Cour, 29, 630.

Debré, R., Marie, J., Soulié, P., and de Font-Réaulx, P. (1936). Bull. Mém. Soc. méd. Hôp., Paris, 52, 749.

Guillain, G., and Mollaret, P. (1932). Presse Méd., 40, 1621.

(1934). Bull. Mém. Soc. méd. Hôp., Paris, 50, 1577.

Guizzetti, P. (1933). Riv. Patol. Nerv., 41, 545.

Lannois, M.; and Porot, A. (1905). Rev. méd., Paris, 25, 853.

Laubry, C., and de Balsac, R. H. (1936). Bull. Mém. Soc. méd. Hôp., Paris, 52, 756.

Ormerod, J. A. (1885). Brain, 7, 105.

Parkinson, J., and Bedford, D. E. (1927). Heart, 14, 195.

Pitt, G. N. (1887). Guy's Hosp. Rep., 44, 369.

Rathery, F., Mollaret, P., and Sterne, J. (1934). Bull. Mém. Soc. méd. Hôp., Paris, 50, 1382.

Russell, D.S. (1941). Personal communication.

Notes of the 38 cases are given in Tables II, III and IV on pages 100 to 102. 


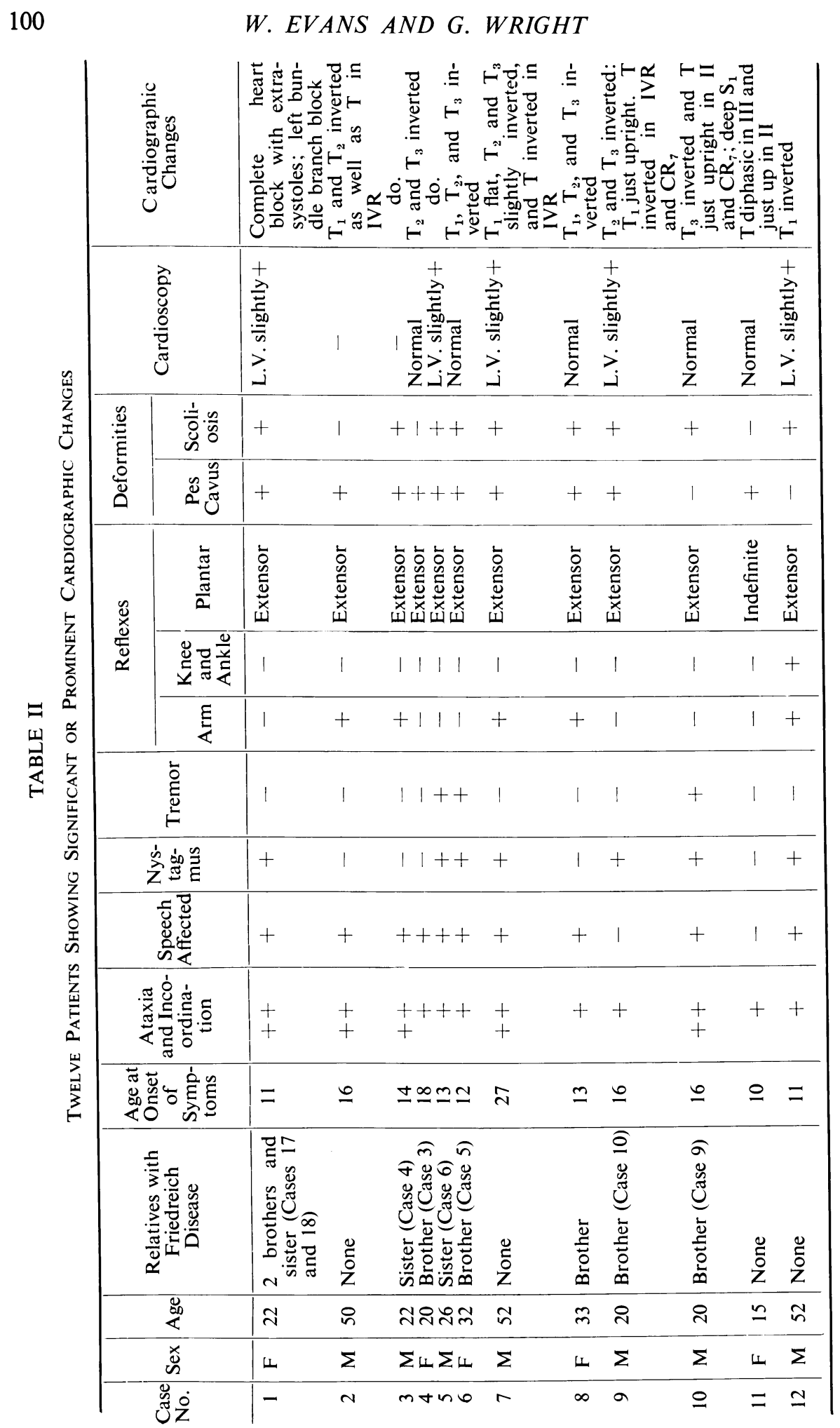

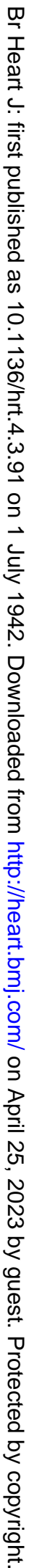


THE ELECTROCARDIOGRAM IN FRIEDREICH DISEASE

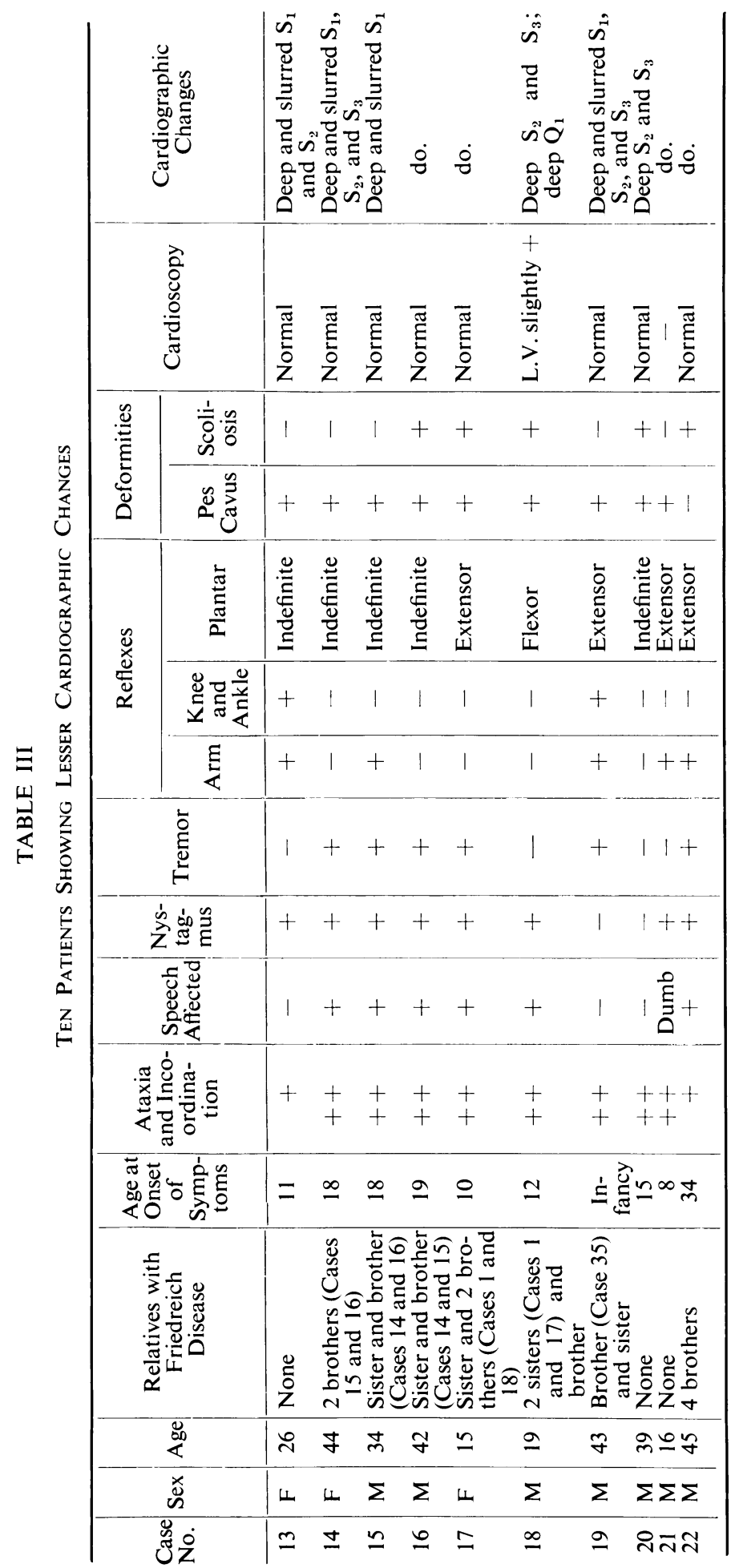




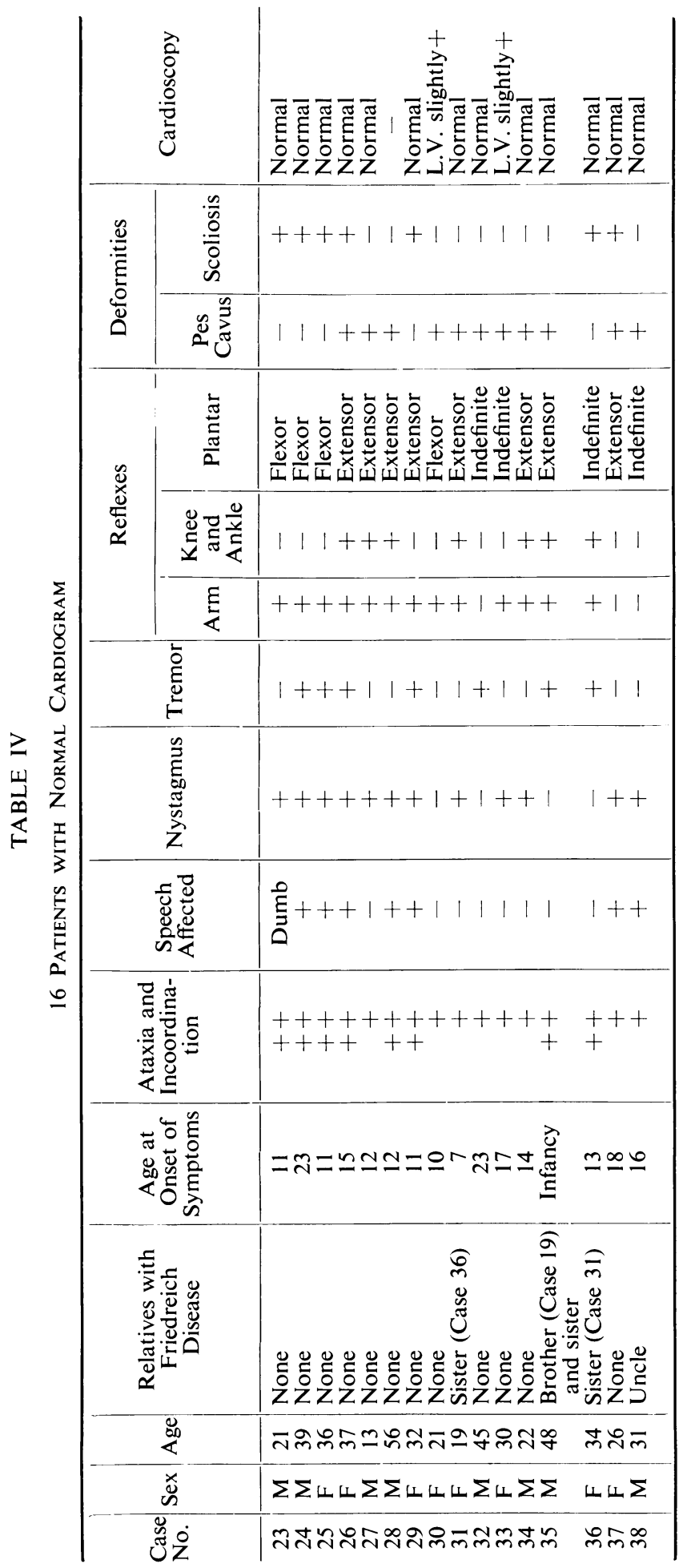

